\title{
The Role of Theory of Mind, Episodic Future Thinking and Creativity In Predicting the Event-based and Time-based Prospective Memory of The Adolescents
}

\author{
Maede Bahri ${ }^{1}$, Maryam Bahri ${ }^{2}$ \\ 1-PhD. Student in Neuroscience, Tehran University of Medical Sciences, Iran. ORCID: 0000-0003-1799-6863 \\ 2-PhD. Student in Neuroscience, Tehran University of Medical Sciences, Iran. ORCID: 0000-0003-4820-2245 \\ E-mail: maryambahri20@yahoo.com
}

Received: 01/08/2018 Accepted: 11/12/2018

\begin{abstract}
Introduction: Prospective memory is an important precursor for independent living adolescents.

Aim: This study aims to the role of theory of mind, episodic future thinking and creativity in predicting the event-based and time-based prospective memory of the Adolescents.

Method: This study was conducted in the form of a correlation pattern. The study population consists of high school students in Azarshahr city in the academic year 2014-2015. In this study, 100 students with a mean age of 16.02 year were selected by multistage cluster sampling. Prospective memory testing, Reading the mind in the eyes test, Autobiographical task and Torrance tests of creativity was used in order to collect data. Then, data were analyzed by Pearson correlations and multi-variable regression.
\end{abstract}

Results: The results showed that theory of mind, episodic future thinking and creativity could predict the event-based and time-based prospective memory.

Conclusion: As a result, we can say that theory of mind, episodic future thinking and creativity operates as an underlying mechanism in the improvement of prospective memory.

Keywords: Theory of mind, Episodic future thinking, Creativity, Event-based prospective memory, Time-based prospective memory, Adolescents

How to cite this article : Bahri, M., Bahri, M. (2019). The Role of Theory of Mind, Episodic Future Thinking and Creativity in Predicting the Event-based and Time-based Prospective Memory of the Adolescents. Shenakht Journal of Psychology and Psychiatry. 2019; 5 (6): 1-12 .

URL :http://shenakht.muk.ac.ir/article-1-479-fa.pdf

Copyright (C) 2018 the Author (s). Published by Kurdistan University of Medical Sciences. This is an open access article distributed under the terms of the Creative Commons Attribution-Non Commercial License 4.0 (CCBY-NC), where it is permissible to download, share, remix, transform, and buildup the work provided it is properly cited. The work cannot be used commercially without permission from the journal. 


\title{
نقش نظريه ذهنه تفكر رويدادى آينده نكر و خلاقيت در ييشبينى حافظه آينده نكر رويداد محور و زمان محور نوجوانان
}

\author{
مائده بحرى '، مريم بحرى \\ ا.دانشجوى د كترى علوم اعصاب، دانشكده فناورى هاى نوين يزشكى، دانشگاه علوم يزشكى وخدمات بهداشتى درمانى تهر ان، ايران.

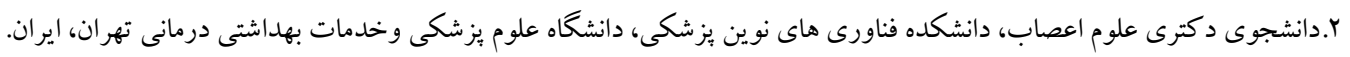 \\ ايميل: maryambahri20@yahoo.com \\ تاريخ بذيرش مقاله: • • \\ تاريخ دريافت مقاله: ·ـ/
}

جكيده

مقدمه: حافظه آينده نكر به عنو ان يكك بيش ساز مهم براى زندگى مستقل نوجو انان محسوب مى شود.

هدف: يزوهش حاضر باه دف بررسى نقش نظريه ذهن، تفكر رويدادى آينده و خلاقيت در ييش بينى حافظه آينده نخر نوجوانان

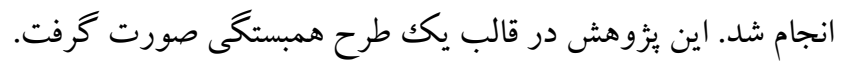

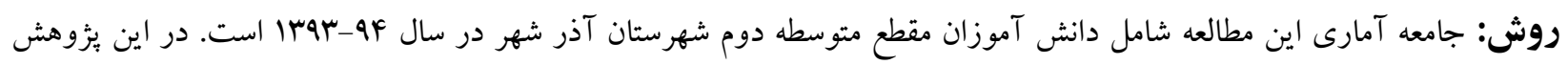

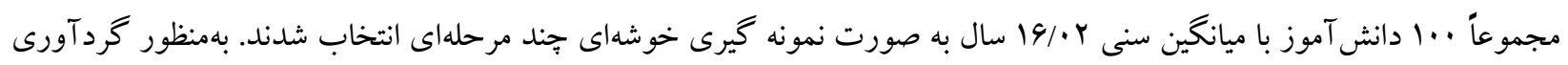
اطلاعات از تكليف حافظه آينده نخر، آزمون ذهن خوانى از طريق تصاوير جشم، تكليف شرح حال و آزمون خلاقيت تورنس استفاده

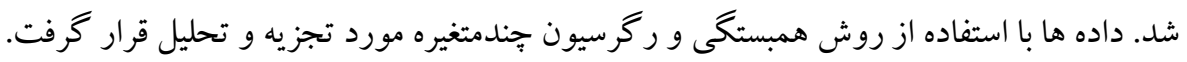
يافته ها: نتايج نشان دادند كه نظريه ذهن، تفكر رويدادى آينده نخرو خلاقيت، حافظه آينده نخر رويداد محور و زمان محور را بيش بينى مى كنند.

نتيجه كيرى: در نتيجه مى توان گفت هر يك از اين متغير ها به عنوان يكك مكانيسم زير بنايى در بهبود عملكرد حافظه آينده نخر عمل مى كنند.

كليدوازه ها: نظريه ذهن، تفكر رويدادى آينده نخر، خلاقيت، حافظهى آينده نخر رويدادمحور، حافظهى آينده نخر زمان محور، نوجوانان 


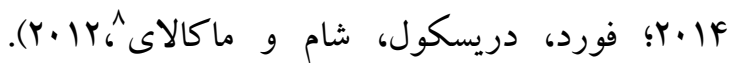
مقلdo

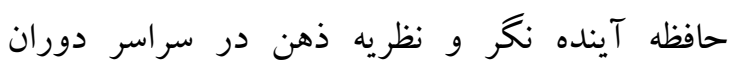
كودكى و نوجوانى بهطور مستمر رشد مى كنيد

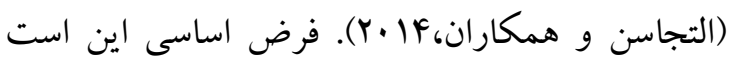
كه توانايى ذهنى دريافت ديدگاه شخصى ديخر بهمنظور دركك باورهاى او، ممكن است به افراد براى كشف ديد كاههاى مختلف زمانى كمكك كند تا افراد موقعيتهاى آينده را تصور كنند (فكر رويدادى آينده) و يا رويدادهاى كذشته را يادآورى كنند (حافظه

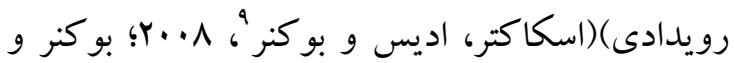

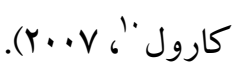

همجِنين بيشنهاد شده است كه تفكر دربارهى آينده ممكن است منجر به تشكيل حافظه آينده نغر شود زيرا وقتى كه نيت به انجام يك عمل شكل مى گيرد، اين

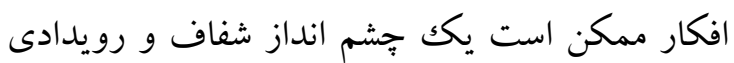
در فرد براى انجام اعمال به وجود آورند (اتانس و

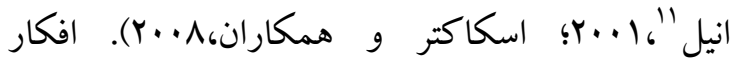
رويدادى آينده نخر شامل شبيه سازى و ساختن سناريوها و رويدادى احتمالى شخصى در زمان آينده

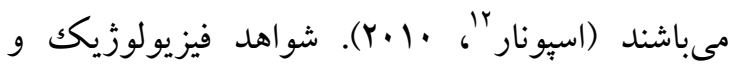
مغزى نيز از الخوى ارتباطى بين حافظه، نظريه ذهن و

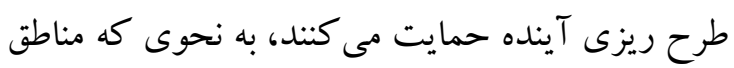
مغزى كه در طرح ريزى آينده درگير هستند (لوب يشانى و آهيانه - كيجگاهى ميانى) با مناطقى كه دري طول تكليف نظريه ذهن و يا بازيابى حافظه شرح حال

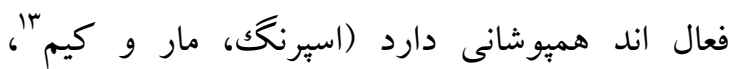

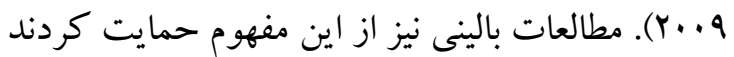
كه يك شبكه مشترك مغزى ممكن است در حافظه رويدادى و افكار رويدادى آينده درگير باشد (اديس، مند

\footnotetext{
${ }^{8}$ Ford, Driscoll , Shum \& Macaulay

${ }^{9}$ Schacter, Addis \& Buckner

${ }^{10}$ Buckner \& Carroll

${ }^{11}$ Atance \& O’Neill

${ }^{12}$ Szpunar

${ }^{13}$ Spreng, Mar \& Kim
}

حافظه آينده نخر به توانايى برنامه ريزى، نگَهدارى و بازيابى نيت هاى برنامه ريزى شده در آينده اشاره دارد

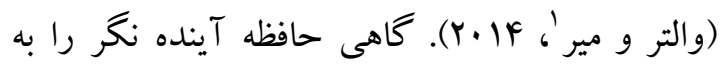
عنوان (يادآورى يادآوردن) توصيف مى كنند (اينستن

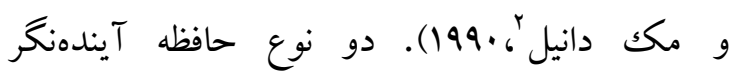
رويدادمحور و زمان محور وجود دارد (وست و

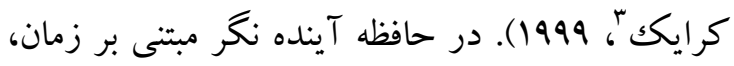
نيت مىبايست در يكك زمان خاص به يادآورده شود (به عنوان مثال، شركت در امتحان در ساعت يازده فردا). در حافظه آينده نخر مبتنى بر رويداد، فرد مىبايست يكك رويداد خاص را در زمان آينده به ياد آورد (به عنوان مثال، يادآورى برقرارى تماس تلفنى با

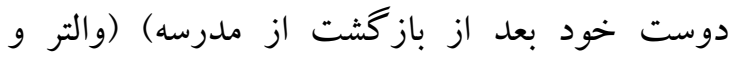

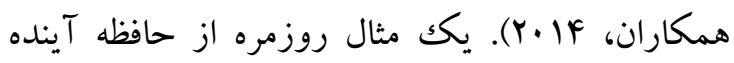
نكر يادآورى خارج كردن غذا از فر است كه فرد آن رادر حين اجراى ساير تكاليف روزمره به ياد مى آورد. حافظه آينده نكر باعث عملكرد موفق روزانه در سراسر

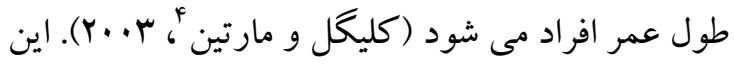
نوع حافظه اجراى مقاصد آينده را توصيف مى كند و 1. به شدت به منطقه يِش يِيشانى (بهطور مثال منطقه

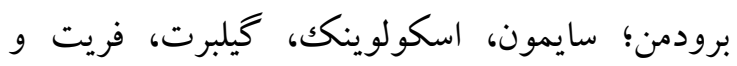

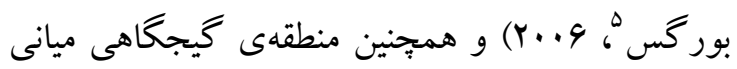
سيستم عصبى (به طور مثال هييو كامٍ) وابسته است

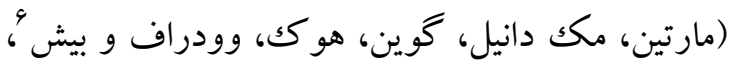

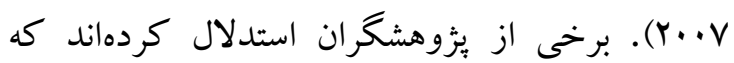
نظريه ى ذهن ممكن است در رشد حافظه آينده نكر

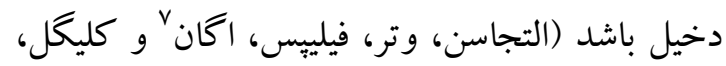

\footnotetext{
${ }^{1}$ Walter \& Meier

${ }^{2}$ Einstein \& McDaniel

${ }^{3}$ West \& Craik

${ }^{4}$ Kliegel \& Martin

${ }^{5}$ Simons, Scholvinck, Gilbert, Frith, \& Burgess

${ }^{6}$ Martin, McDaniel, Guynn, Houck, Woodruff \& Bish

${ }^{7}$ Altgassen, Vetter, Phillips \& Akgün
} 
حاضر بررسى نقش نظريه ذهن، تفكر رويدادى آيندهو خلاقيت در بيشبينى حافظهى آينده نخر رويدادمحور و زمان محور در نوجوانان است.

روش

يُزوهش حاضر از تحقيقات توصيفى (غير آزمايشى) و از نوع همبستكى است. جامعه آمارى اين مطالعه شامل دانش آموزان شهرستان آذر شهر در سال

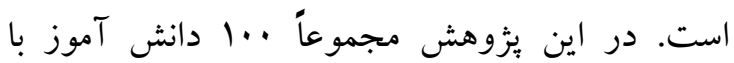

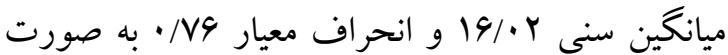

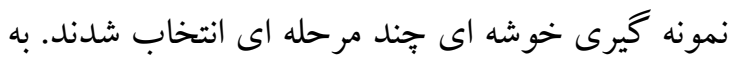
اين ترتيب كه ابتدا از بين مدارس متوسطه دوم شهرستان آذرشهر ابتدا و دبيرستان انتخاب شدند و در

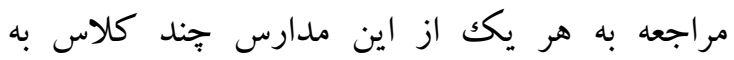
تصادف انتخاب شدند. معيارهاى ورود به يثوهش عبارت بود از: مشغول به تحصيل بودن در مقطع

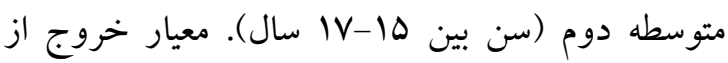
يثزوهش عبارت است از: غيبت دانش آموز در يكى از دو روز يزوهش و سابقه بيمارى روانشناختى. به منظور اجراى يُزوهش ابتدا مجوز هاى لازم اخذ شد. در مرحله ى بعد، يس از مشخص شدن نمونه مورد

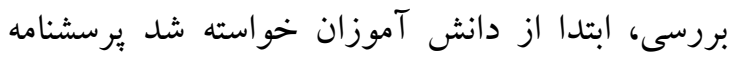

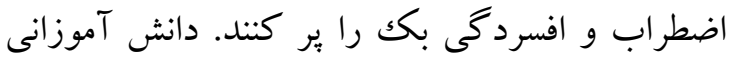

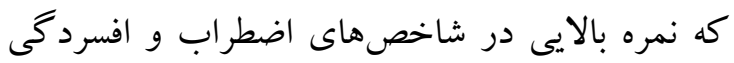
كسب كردند از يزوهش حذف شدند. سيس اجراى آزمون ها در دو نوبت (دو روز) صورت گرفت. در حرد حرد مرحله اول از افراد خواسته شد تا تكليف حافظه آينده نكر و آزمون ذهن خوانى از طريق تصاوير جشم را تكميل كنند، در مرحله دوم آزمودنىها تكاليف شرح حال و آزمون خلاقيت تورنس را انجام دادند. لازم به ذكر است كه براى جلو گيرى از اثرات ترتيب اجراى

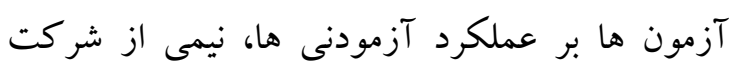

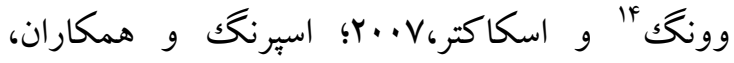

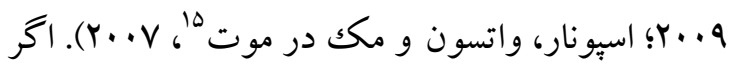
جه آينده غير قابل بيش بينى است، اما افراد مى توانند حالات بالقوه آينده را در ذهن خود شبيهسازى كنند

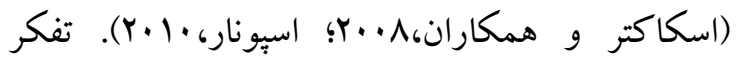
آينده نخر داراى ارزش انطباقى است، به عنوان مثال، افر اد عواقب احتمالى اعمال خود را قبل از اقدام در نظر

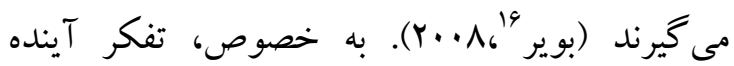
باعث انعطاف يذيرى در رفتار مى شود (سادندورف و

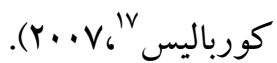
از طرفى، ساختن بازنمايى هاى ذهنى از آينده با بالت

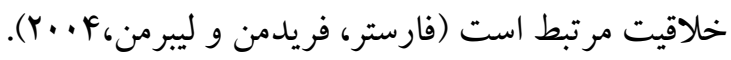
وقتى يكك فرد به آينده فكر مى كند، احتمالات نامحدود سناريوهاى فرضى آينده را به صورت خلاقانه

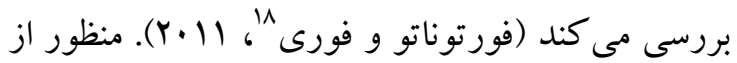
خلاقيت، فرآيندهاى هاى عمليات ذهنى جديد و ابداع توليدات مفيد است. خلاقيت به تدريج و همراه با رشد

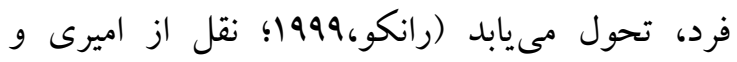
اسعدى، ومץ|). با توجه به ارتباط بين افكار رويدادى

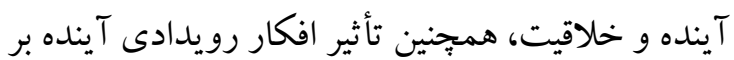
حافظه آينده نخر مى توان اين گونه فرض كردين كرد كه

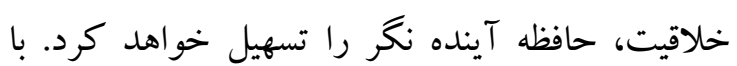
توجه به رشد هريكك از اين كاركردهاى شناختى در طول دوران نوجوانى، معلمان مىبايست نسبت به رشد تدريجى توانمندى شناختى نوجوانان از جمله حافظه

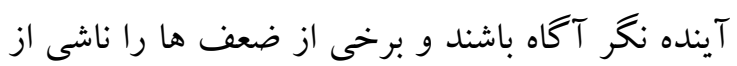
رشد نايافتحى توانمندى هاى شناختى در اين سنين بداند. با توجه به مطالب ذكر شده و اهميت اين نوع

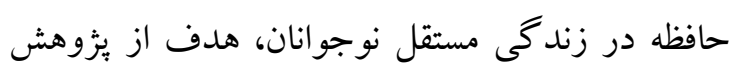

\footnotetext{
${ }^{14}$ Wong

${ }^{15}$ Watson \& McDermott

${ }^{16}$ Boyer

${ }^{17}$ Suddendorf \& Corballis

${ }^{18}$ Fortunato \& Furey
} 
فعل منفى در سؤالات كنجانده شده بود، بنابراين حداقل و حداكثر نمره افراد در اين قسمت · و ·ب بود. در قسمت زمان محور هم از آن ها خواسته شد بعد از

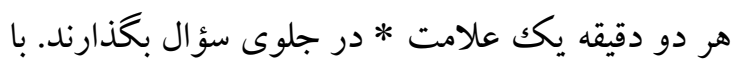

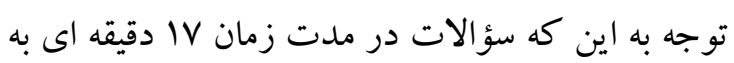
افراد ارائه مى شد، حداقل و حداكثر نمره افراد در اين

$$
\text { قسمت هم · تا ^بود. }
$$

آزمون ذهنخوانى از طريق تصاوير جشمز بارون-

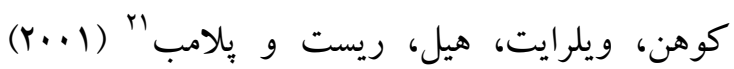
نسخه كاميوترى تست تجديد نظر شده ذهن خوانى از طريق جشم ها را براى سنجش نظريه ذهن ابداع كردند. در نسخه اصلاح شده ذهن خوانى از طريق تصاوير جشمى، 4س تصوير (شامل عكسهايى از ناحيه جشم هنريشه هاى زن و مرد) و جهار گزينه شامل

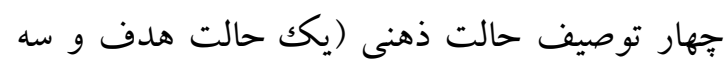
حالت انحرافى با همان ارزش هيجانى) ارائه مىشود.

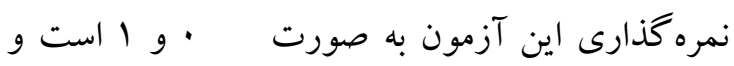

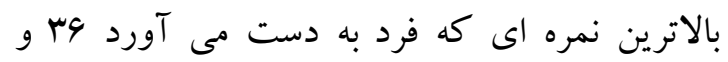

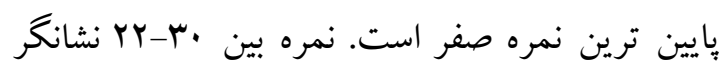

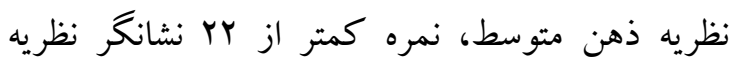
ذهن بايين و نمره بالاتر از •r نشانكر نظريه ذهن

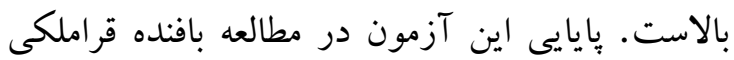

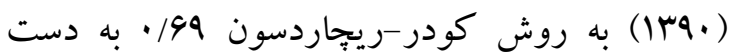

تكليف شرححال "rا! براى سنجش تفكر رويدادى آينده نخر شركت كنند كان از تكليف شرح حال آر گمبيو،

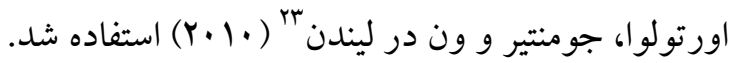
اين تكليف به سه بخش تقسيم شد، در بخش اول از تكليف سيال rF استفاده شد. به اين صورت بخد كه از

\footnotetext{
${ }^{21}$ Baron-Cohen, Wheelwright, Hill, Raste \& Plumb ${ }^{22}$ Autobiographical

${ }^{23}$ Argembeau, Ortoleva, Jumentier \& Van der Linden ${ }^{24}$ Fluency task
}

كنند كان ابتدا تكاليف نوبت دوم را انجام دادند و سبس تكاليف مرحله اول را تكميل كردند. اجراى آزمون ها براى هر نفر در نوبت اول ·r دقيقه و در نوبت دوم 10 دقيقه طول كشيد. بعد از تكميل و جمع آورى داده ها،

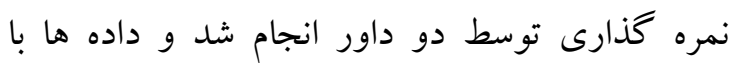
استفاده از نرم افزار SPSS rY مورد تجزيه و تحليل قرار گرفتند. براى تحليل داده ها از آمارهاى توصيفى، ضريب همبستخى ويرسون و تحليل رگرسيون جند متغيرى استفاده شد. به منظور گردآورى اطلاعات داده هاى اين يزٔوهش از ابزارهاى زير استفاده شد:

ابزار تكليف حافظه آينده نتر: براى اجراى تكليف حافظه آينده نگر از تكليفى كه وانگگ، كليگل، ينگك و ليو 19

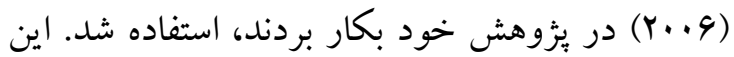
تكليف از دو بخش تشكيل مى شود: ابتدا در بخش

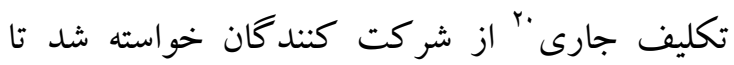
يرسشنامهاى را كه به صورت شنيدارى به آن ها ارائه مى شد، يركنند، سؤالها به صورت تصادفى از يرسشنامهاى مختلف انتخاب كرديد، هر سؤال به صورت فايل صوتى ضبط شده در مدت زمان جهار ثانيه خوانده مى شد و همجنين بين هر سؤال فاصله جهار ثانيه اى وجود داشت. آزمودنى ها موظف بودند به سؤالات گوش دهند و ياسخ خود را در بر گه ياسخى كه به آنها داده مىشد علامت بزنند. بخش دوم-

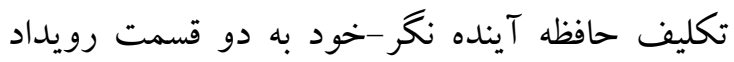
محور و زمان محور تقسيم شد. در قسمت رويدادمحور از افراد خواسته شد تا هنگگام ير كردن برسشنامه هر كاه فعل منفى (به طور مثال، انجام نمى شود) را شنيدند، دو علامتل در جلوى سؤال بكذارند. در مجموع بيست

\footnotetext{
${ }^{19}$ Wang, Kliegel, Yang \& Liu ${ }^{20}$ ongoing task
} 
افراد در اين بخش V بود. به طور ايده آل، ضريب

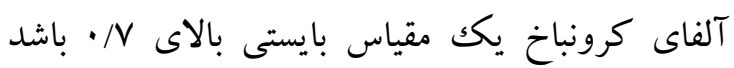

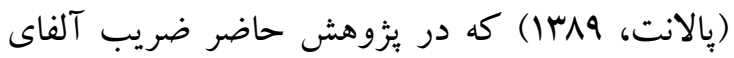
كرونباخ اين تكليف Ar/ • است. آزمون خلاقيت تورنس: اين آزمون توسط تورنس (1999) ابداع شده است و داراى •9 سؤال است كه هر لورئ سؤال مشتمل بر سه بِاسخ است كه نمره هاى ا تا سم

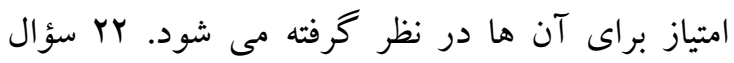
مربوط به ابتكار، 19 سؤال براى آزمودن سيالى، 11 سؤال براى انعطاف يذيرى و ال سؤال هم براى آزمودن

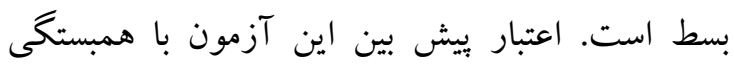

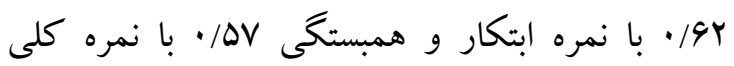
خلاقيت به دست آمده است (تورنس، $999 ؛$ حميدى، شهمير، محمدى و دهنوى، اهبا). در ايران ضريب اعتبار محاسبه شده سؤالات براى كل آزمون /AV • به دست آمده است كه از نظر آمارى معنادار است (رضايى و منوجهرى، IrNV). در بُزوهش حاضر

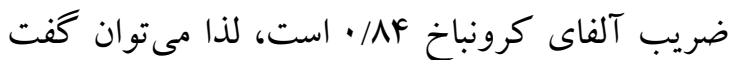
كه اين مقياس از همسانى درونى خوبى برخوردار

\section{يافته ها}

براى تجزيه و تحليل آمارى داده هاى گردآورى شده، ابتدا از آمار توصيفى، ضريب همبستخى بيرسون و و سبس رگرسيون جند متغيره استفاده گرديد. جدول ميانگين و انحر اف استاندارد متغيرهاى حافظه آينده نغر رويداد محور، حافظه آينده نگر زمان محور، نظريه ذهن، شاخص سيالى آينده، شاخص رويداد هاى ويزه

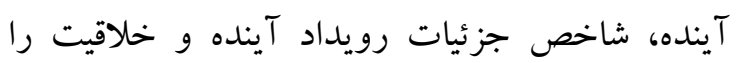

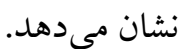

آزمودنى ها خواسته شد تا درباره ى دو دورهى زمانى در آينده خود (سال آينده و ه-·-1 سال آينده) فكر كنند. براى هر كدام از دوره ها به افراد •9 ثانيه زمان داده شد تا رويداد هايى را كه ممكن است در آينده اتفاق بيافتد، يادداشت كنند. نمرهى افراد در اين بخش روتش مبتنى بر كل تعداد رويدادهاى به ياد آورده شده در هر دوره زمانى بود و مجموعاً رويدادهاى دو دوره باهم

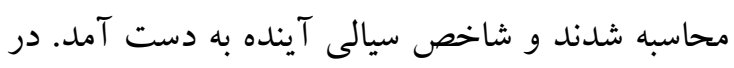
بخش دوم- تكليف ويزه به (رويدادهاى ويزه)- يكك

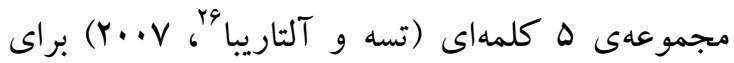

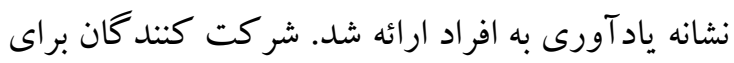

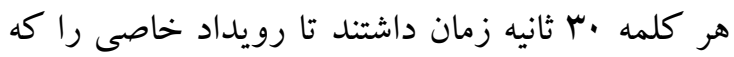
ممكن است در آينده شان اتفاق بيافتد، يادداشت كنند. براى نمره گذارى فقط به رويداد هايى كه در زمان و

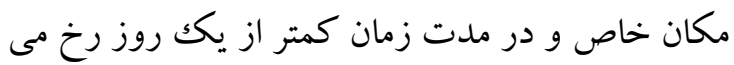

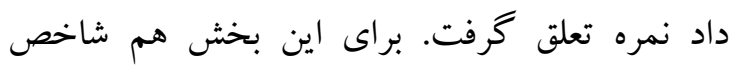
رويدادهاى ويزه آينده به دست آمد و بالاترين نمره افراد در اين بخش -تعداد رويدادهاى نوشته شده-

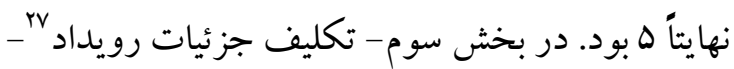
دو جمله به عنوان نشانه به شركت كنند كان ارائه شد (تصور كنيد كه در آينده دوست خود را ملاقات خواهيد كرد؛ تصور كنيد كه در آخر هفته آينده جه كارى را انجام خواهيد داد) و از آن ها خواسته شد تا رويداد هاى خاص مربوط به آينده را با شرح

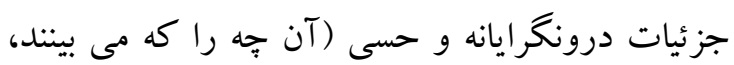
مى شنوند و احساس مى كنند) بيان كنند. نمره كذارى (جنى هم بر اساس يكك مقياس V ليكرتى به ويز گیى هاى يديدار شناختى جملات (جزئيات بصرى، وضوح مكان و زمان و احساس هيجانى) محاسبه شد. در اين بخش شاخص جزئيات آينده به دست آمد و حداكثر نمره

\footnotetext{
${ }^{25}$ Specificity task

${ }^{26}$ Tse \& Altarriba

${ }^{27}$ Episodic details task
} 


\begin{tabular}{|c|c|}
\hline ميانكين (انحراف معيار) & متغير \\
\hline$(F / 9 r) 10 / \pi r$ & حافظه آينده نكر رويداد محور \\
\hline$(r / r q) r / r q$ & حافظه آينده نكر زمان محور \\
\hline$(r / 90) 19 / r r$ & 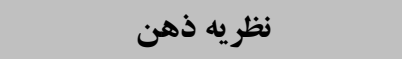 \\
\hline$(I / N F) r / M$ & شاخص سيالى آينده \\
\hline$(\cdot / 11) \cdot / 9 r$ & شاخص رويداد هاى ويزه آينده \\
\hline$(1 / F I) Y / Y V$ & شاخص جزئيات رويداد آينده \\
\hline$(1 \mid / \Delta \Delta) \mid r V / \cdot \Delta$ & خلاقيت \\
\hline
\end{tabular}

به منظور بررسى ارتباط بين متغير هاى بثوهش ماتريس همبستكى بين اين متغير ها در جدول Y آورده شده است.

\begin{tabular}{|c|c|c|c|c|c|c|c|}
\hline$r$ & 9 & $\Delta$ & p & $r$ & $r$ & 1 & متغير \\
\hline & & & & & & 1 & حافظه آينده نكر رويداد محور \\
\hline & & & & & 1 & $\cdot / \mathscr{ศ} \Lambda^{* * * *}$ & حافظه آينده نكر زمان محور \\
\hline & & & & 1 & $\cdot / M Y^{*}$ & $\cdot / r^{* * *}$ & 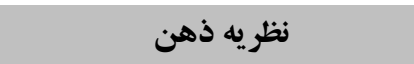 \\
\hline & & & 1 & $\cdot \mid \mu^{* * * * *}$ & $\cdot / \Re \Lambda^{* * *}$ & $\cdot / 41^{* * * *}$ & شاخص سيالى آينده \\
\hline & & 1 & $\cdot / q^{* * * *}$ & $\cdot / \Lambda^{* *}$ & $\cdot / \mu q^{* * * *}$ & $\cdot / r r^{* * *}$ & شاخص رويداد هاى ويزه آينده \\
\hline & 1 & $\cdot / 1 \Lambda$ & $\cdot / Y \Lambda^{* * * * *}$ &.$/ \cdot 9$ & $\cdot / F F^{* * *}$ & $\cdot / T V^{* * * *}$ & شاخص جزئيات رويداد آينده \\
\hline 1 & $\cdot / I V$ & $\cdot / \mathrm{IV}$ & $\cdot / r 4^{* * *}$ &.$/ 1 r$ & $\cdot / \mu^{* * * *}$ & $\cdot / r 4^{* * *}$ & خلاقيت \\
\hline
\end{tabular}

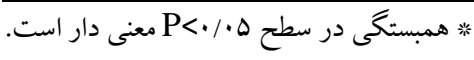

و نظريه ذهن در سطح ه •/P همبستخى مثبت معنادار وجود دارد.

در ادامه، به منظور بررسى نقش هر يكك متغير هاى يزّوهش در بيش بينى حافظه آينده نكر رويداد محور و زمان محور، نتايج تحليل ركرسيون اين متغير ها در ارتباط با حافظه آينده نخر رويداد محور و زمان محور

$$
\text { در جدول هاى ا، Fأ و ه آورده شده اند. }
$$

همان كونه كه در جدول Y مشاهده مىشود كه بين حافظه آينده نگر رويداد محور با حافظه آينده نكر زمان محور، نظريه ذهن، شاخص سيالى آينده، شاخص رويدادهاى ويزه آينده، شاخص جزئيات رويداد آينده و خلاقيت در سطح 1 + P> همبستخى مثبت معنادار وجود دارد. همجينين بين حافظه آينده نگر زمان محور

\begin{tabular}{|c|c|c|c|c|c|c|}
\hline${ }^{Y} \mathbf{R}$ & $\mathbf{R}$ & سطح معنادارى & $\mathbf{T}$ & Beta & متغير ييش بين & متغير ملاكى \\
\hline $.1 \cdot 0$ & $\cdot / r \mu$ & $\cdot / \cdot r$ & $r / T V$ & $\cdot / 79$ & نظريه ذهن & حافظه ى آينده نكر رويداد محور \\
\hline$\cdot 1 \cdot \Delta$ & $\cdot / r r$ & $\cdot / \cdot r$ & $r / Y \Delta$ & $\cdot / \mathrm{F}$ & نظر يه ذهن & حافظه ى آينده نكر زمان محور \\
\hline
\end{tabular}

همبستكى Yץ/ • توانست حدود هـ/ • درصد تغييرات مربوط به حافظه آينده نخر زمان محور را تبيين نمايد. همجنين نتايج جدول نشان مى دهد كه نظريه ذهن مى
نتايج جدول r نشان مى دهد كه نظريه ذهن با ضريب همبستگى بر/· توانست حدود هـ/ • درصد تغيرات مربوط به حافظه آينده نكر رويدادمحور و با ضريب 
تواند حافظه آينده نخر رويداد محور و زمان محور را نظريه ذهن به صورت مثبت حافظه آينده نخر ييش بينى كند. نكاهى به ضرايب بتا نشان مى دهد كه رويدادمحور و زمان محور را بيش بينى مى كند.

\begin{tabular}{|c|c|c|c|c|c|c|}
\hline $\mathbf{R}$ & $\mathbf{R}$ & معنادارى سطح & $\mathbf{T}$ & Beta & متغير بيش بين & متغير ملاكى \\
\hline & & $\cdot / \cdot \cdot 1$ & $r / F i$ & $\cdot / r F$ & شاخص سيالى آينده & \\
\hline \multirow[t]{3}{*}{$\cdot / r$} & $\cdot / 4 \Delta$ & NS & $\cdot / 9 \mathrm{~V}$ & .1 .9 & شاخص رويداد هاى ويزه آينده & حافظه آينده نكر رويداد محور \\
\hline & & NS & $1 / 94$ &.$/ 19$ & شاخص جزئيات رويداد آينده & \\
\hline & &.$/ \cdot 1$ & $r / r r$ & $\cdot \pi \cdot$ & شاخص سيالى آينده & \\
\hline \multirow[t]{2}{*}{$\cdot / 4$} & .191 &.$/ \cdot 1$ & $r / F T$ & $\cdot / r 1$ & شاخص رويداد هاى ويزّه آينده & حافظه آينده نكر زمان محور \\
\hline & & $\cdot / \cdots$ & $r / v q$ & $\cdot / r r$ & شاخص جزئيات رويداد آينده & \\
\hline
\end{tabular}

تغييرات مربوط به حافظه آينده نخر زمان محور را تبيين

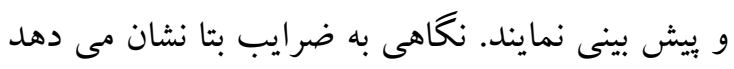
كه اين شاخص ها به صورت مثبت حافظه آينده نئر رويدادمحور و زمان محور را بيش بينى مى كنئد.
نتايج جدول F نشان مى دهد كه افكار رويدادى آينده

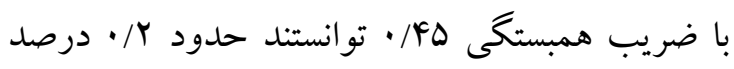

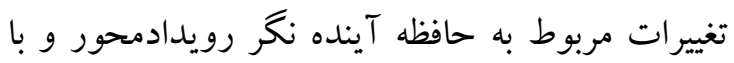

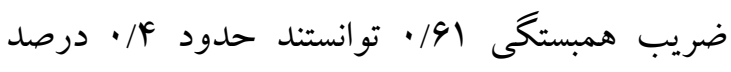

جدول ه. نتايج تحليل ركرسيون خلاقيت در ارتباط با حافظه ى آينده نغر رويداد محور و زمان محور

\begin{tabular}{|c|c|c|c|c|c|c|}
\hline $\mathbf{R}$ & $\mathbf{R}$ & سطح معنادارى & $\mathbf{T}$ & Beta & متغير يِيش بين & متغير ملاكى \\
\hline$\cdot / \cdot \mathrm{V}$ & $\cdot / Y 9$ & $\cdot \cdots \wedge$ & $r / V I$ & $\cdot / r 4$ & خلاقيت & حافظه ى آينده نكر رويداد محور \\
\hline$\cdot / 11$ & 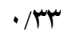 &.$/ \cdot 1$ & $r / 4 \Delta$ & 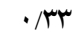 & خلاقيت & حافظه ى آينده نكر زمان محور \\
\hline
\end{tabular}

هدف از بثزوهش حاضر بررسى نقش نظريه ذهن، تفكر

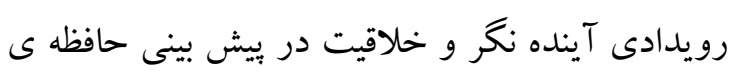

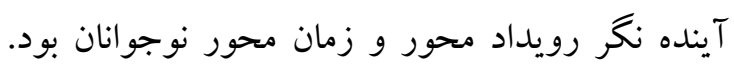
يافته هاى به دست آمده از اين بيزوهش نشان دادند كه ونه نظريه ذهن حافظه آينده نخر رويداد محور و زمان محور را بيش بينى مى كند. اين نتيجه با يافته هاى

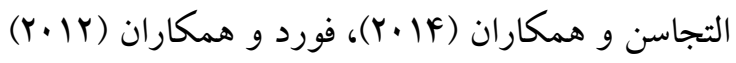

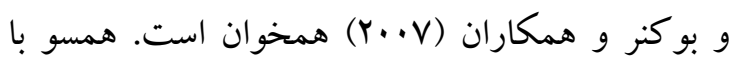

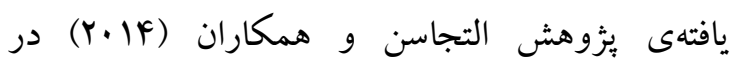
يثزوهش خود نشان دادند كه بزرگكسالان جوان در تكاليف نظريه ذهن و حافظه آينده نگر عملكرد بهترى ئرى نسبت به نوجو انان دارند. همجِنين همسو با يافته هاى

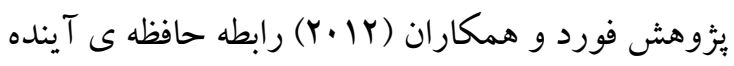

نتايج جدول ه نشان مى دهد كه خلاقيت با ضريب

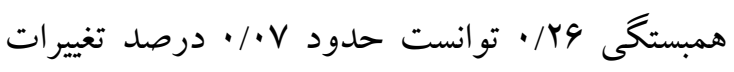
مربوط به حافظه آيندهنگر رويدادمحور و با ضريب لهب همبستخى سر/· توانست حدود مربوط به حافظه آينده نكر زمان محور را تبيين نمايد. همجنين نتايج جدول نشان مى دهد كه خلاقيت مى بـ

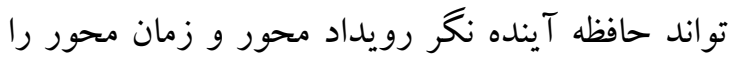
بيش بينى كند. نگاهى به ضرايب بتا نشان مى دهد كه

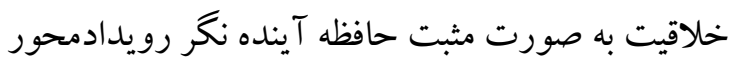
و زمان محور را بيش بينى مى كند. 
اعمال برنامه ريزى شده خودشان در آينده فكر مى كنند و علاوه بر اين، با توجه به همبستكى هاى ممكن بين رشد نظريه ذهن و تشكيل نيت، نظريه ذهن در طول دوران نوجوانى، واريانسهاى عملكرد حافظه آينده نكر را بيش بينى مى كند.

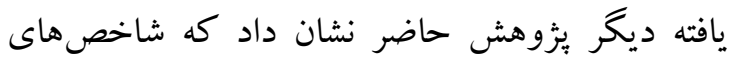
تفكر رويدادى آينده نخر توانستند به صورت مثبت

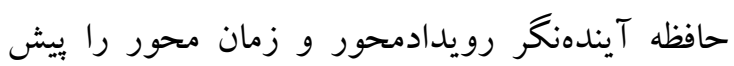
بينى كنند. البته لازم به ذكر است كه در اين بين شاخص رويدادهاى ويزه آينده و شاخص جزئيات

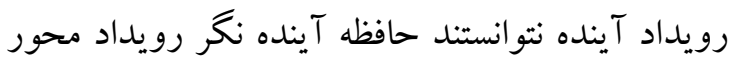

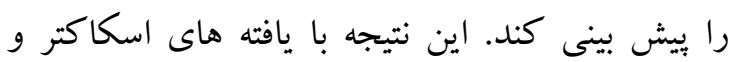

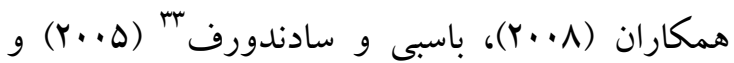
اتانس و همكاران (Y..... همسو است. همسو با يافته

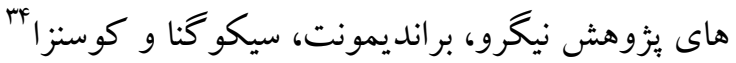

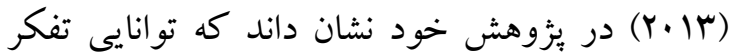
رويدادى آينده نگر و سن به طور قابل توجهى عملكرد حافظه آينده نخر را، مستقل از توانايى هاى حاف حافظه

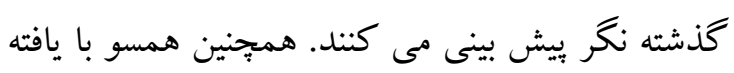

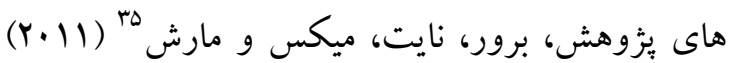
در ئزوهش خود نشان دادند كه عملكرد حافظه آينده نكر شركت كنند گان، بعد از تصويرسازى ذهنى موقعيتى كه فرد در آن تكليف حافظه ى آينده نخر را انجام مى دهد، افزايش مى يابد. اين نتايج، ارتباط شكل

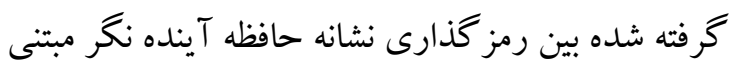

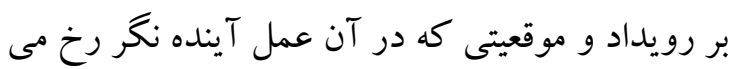
دهد را نشان مى دهند. باز هم ياراسكوايدس، مور گان،

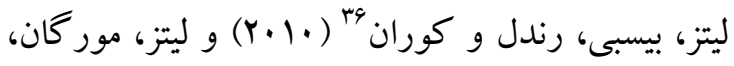

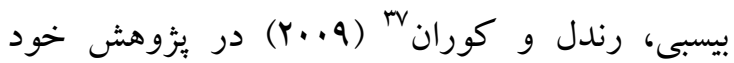

${ }^{33}$ Busby \& Suddendorf

${ }^{34}$ Nigro, Brandimonte, Cicogna \& Cosenza

${ }^{35}$ Brewer, Knight, Meeks \& Marsh

${ }^{36}$ Paraskevaides, Morgan, Leitz, Bisby \& Rendell

${ }^{37}$ Leitz, Morgan, Bisby, Rendell \& Curran
نكر با نظريه ذهن و كار كردهاى اجرايى كود كان F تا

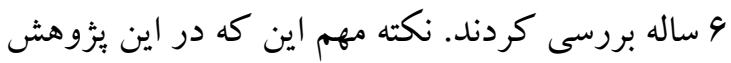
نظريه ذهن به طور قابل توجهى واريانس عملكرد

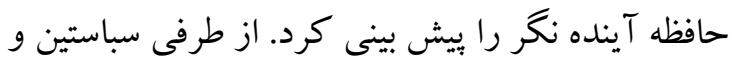

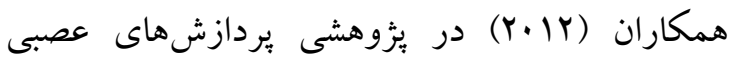
مر تبط با نظريه ذهن شناختى و عاطفى نوجوانان 19-11

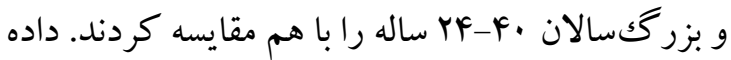
هاى حاصل از تصويرسازى تشديد مغناطيسى كاركردى ^^در اين هيزوهش نشان دادند كه در طول انجام دادن تكاليف نظريه ذهن علاوه بر فعال شدن مناطق كلاسيك مربوط به نظريه ذهن در مغز، قشر بيش

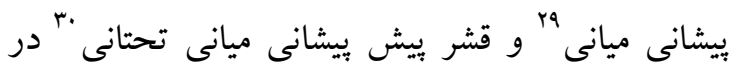
هنگام اجراى تكاليف عاطفى نظريه ذهن فعال شدند. همجنين فعاليت قشر بيش بيشانى ميانى تحتانى در بين

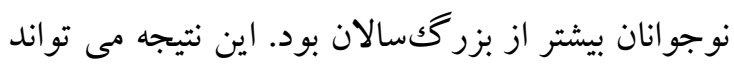

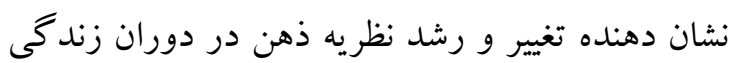
باشد. دادههاى رفتارى (دومونتيل، إيرلى و بلكمور "آ،

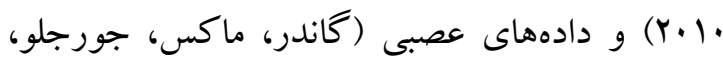

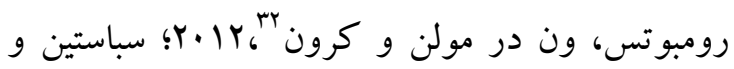

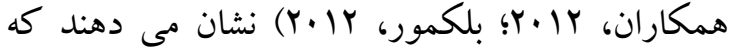
نظريه ذهن همجِنان در اواخر دوران كودكى، نوجوانى و ورود به جوانى به رشد خود ادامه مى دهند. بنابراين توانايى ذهنى دريافت ديد كاه شخصى ديخر ان به منظور دركى باورهاى آن ها، منجر به كشف ديدگاههاى مختلف زمانى مى شود تا افراد موقعيت هاى آينده را تصور كنند (فكر رويدادى آينده) و يا رويدادهاى كذشته را يادآورى كنند (حافظه رويدادى). اين يافته را

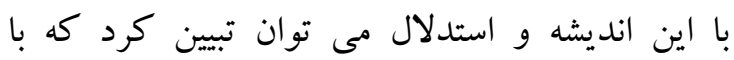
افزايش توانايى نظريه ذهن، افراد بهتر در مورد انجام

\footnotetext{
${ }^{28}$ Functional Magnetic Resonance Imaging

${ }^{29} \mathrm{mPFC}$

${ }^{30}$ vmPFC

${ }^{31}$ Dumontheil, Apperly \& Blakemore

${ }^{32}$ Gunther, Macks , Gueroglu, Rombouts, Van der Molen \& Crone
} 
در نهايت يُوهش حاضر نشان داد كه نظريه ذهن، افكار رويدادى آينده و خلاقيت مى تو انند حافظه آينده نكر رويداد محور و زمان محور را در نوجوانان يبشبينى نمايند. در نتيجه شايد بتوان كفت هريك از اين متغير ها به عنوان يكك مكانيسم زير بنايى در بهبود دئد

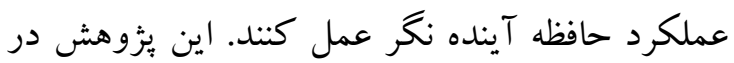
قالب يكك طرح همبستخى صورت گرفته است، بنابر اين از هر گونه استنباط على در مورد اين يافته ها بايد خوددارى شود. در اين يُزوهش براى بررسى حافظه آينده نگر از يكك تكليف مدادكاغذى استفاده شده است؛ ييشنهاد مى شود در إزوهش هاى بعدى از

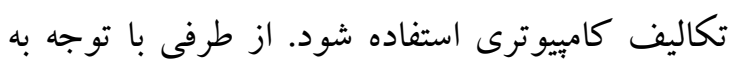
اين فرض كه حافظه آينده نگر در طول نوجوانى به رشد خود ادامه مى دهد بيشنهاد مى شود در يزوهش هاى بعدى، آزمودنى ها به طور مقطعى در سنين متفاوت نوجوانى باهم مقايسه شوند.

\section{References}

Addis, D., Wong, A., \& Schacter, D. (2007). Remembering the past and imagining the future: Common and distinct neural substrates during event construction and elaboration. Neuropsychologia, 45, 1363-1377.

Amiri, Sh \& Asadi, Samaneh (2007). The evolution of creativity in children. Cognitive Sciences, 9(4), 26-32. [Persian].

Argembeau, A., Ortoleva, C., Jumentier, S., \& Van der Linden, M. (2010). Component processes underlying future thinking. Memory and Cognition, 38(6), 809-819.

Atance, C. M., \& O'Neill, D. K. (2001). Episodic future thinking. Trends in Cognitive Sciences, 5 , 533-539.

Bafandeh,H. (2011). The study of the defect of the theory of mind in positive and negative schizophrenics
دريافتند كه شركت كنند كان در كروه آزمايش كه عمل قصد شده خود را به صورت ذهنى شبيه سازى كردند در مقايسه با گروه كنترل عملكرد حافظه ى آينده نخر بالاترى داشتند. شايد بتوان اين يافته را بردرد

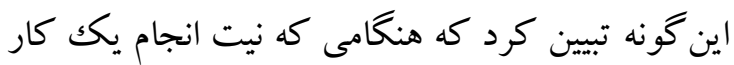

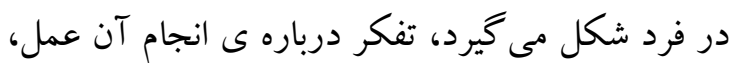
منجر به ايجاد يكك جشم انداز روشن و شفاف از انجام

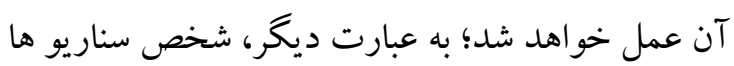

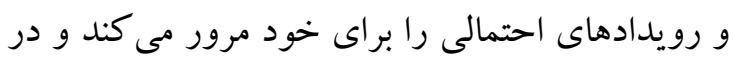
واقع آن عمل را در ذهن شبيه سازى مى كند.

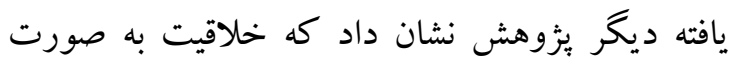

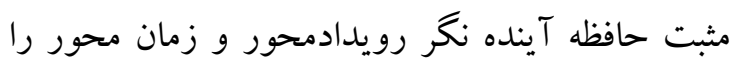

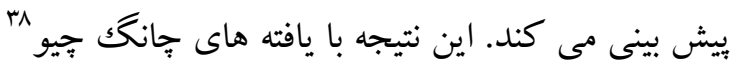

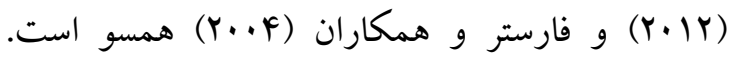

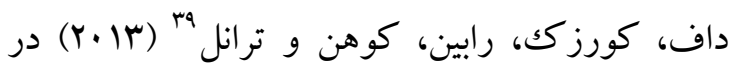

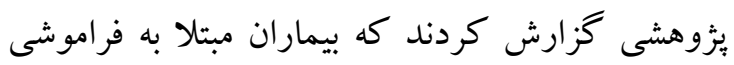
كه دجار آسيب در هيبو كامب دوطرفه بودند، در انجام تكاليف حافظه و تكليف خلاقيت تورنس ناتوان بودند.

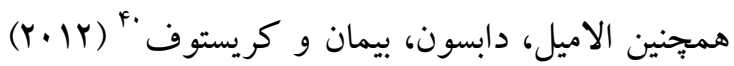
در بثزوشى كه از MRI كاركردى استفاده كردند، نشان دادند مناطق مغزى كه به طور معمول مرتبط با حافظه هستند از جمله هييو كامب، هنگگامى كه افراد

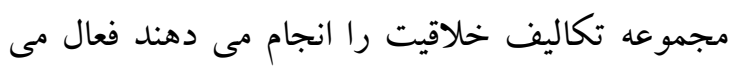
شود. اين يافته را مى توان اينكونه تبيين كرد كه

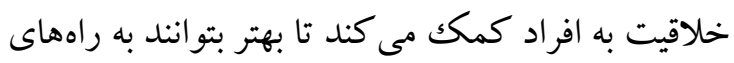
مختلف رسيدن به اهداف و اعمال خود در آينده فكر كنند و اين مشغول بودن مغز با آن اعمال به افر اد كمك مى كند تا حافظه آينده نگر بهترى داشته باشند.

نتيجه كيرى

\footnotetext{
${ }^{38}$ Chung Chiu

${ }^{39}$ Duff, Kurczek, Rubin, Cohen, and Tranel

${ }^{40}$ Ellamil, Dobson, Beeman, \& Christoff
} 
its comparison with healthy people. $\mathrm{PhD}$ dissertation, Faculty of Psychology and Educational Sciences, Tabriz University. [Persian].

Baron-Cohen, S., Wheelwright, S., Hill, J., Raste, Y \& Plumb, I. (2001). The Reading the Mind in the Eyes. Test revised version: a study with normal adults, and adults with Asperger syndrome or high-functioning autism. The Joumal of Child Psychology and Psychiatry and Allied Disciplines, 42, 2, 241-51.

Blakemore, S. J. (2012). Imaging brain development: The adolescent brain. Neurolmage, 61, 397-406.

Boyer, P. (2008). Evolutionary economics of mental time travel? Trends in Cognitive Sciences, 12, 219-224.

Brewer, G. A., Knight, J., Meeks, J. T., \& Marsh, R. L. (2011). On the role of imagery in event-based prospective memory. Consciousness and Cognition, 20,901-907.

Buckner, R. L., \& Carroll, D. C. (2007). Selfprojection and the brain. Trends in Cognitive Sciences, 11,49-57.

Busby, J., \& Suddendorf, J. (2005). Recalling yesterday and predicting tomorrow. Cognitive Development, 20, 362-372.

Chung Chiu, F.A. (2012). Fit between future thinking and future orientation on creative imagination. Thinking Skills and Creativity, 7, 234-244.

Duff, M. C., Kurczek, J., Rubin, R., Cohen, N. J., \& Tranel, D. (2013). Hippocampal amnesia disnupts creative thinking. Hippocampus, 23, 1143-1149.

Dumontheil, I., Apperly, I. A., \& Blakemore, S. J. (2010). Online usage of theory of mind continues to develop in late adolescence. Developmental Science, 13, 331-338.

Einstein, G. O., \& McDaniel, M. A. (1990). Normal aging and prospective memory. Journal of Experimental Psychology: Learning, Memory, and Cognition, 16, 717-726.

Ellamil, M., Dobson, S., Beeman, M., \& Christoff, K. (2012). Evaluative and generative modes of thought during the creative process. Neurolmage, 59, 1783-1794.

Farster, J., Friedman, R., \& Liberman, N. (2004). Temporal construal effects on abstract and concrete thinking: consequences for insight and creative cognition. Joumal of Personality and Social Psychology, 87, 177-189.

Ford, R. M., Driscoll, T., Shum, D., \& Macaulay, C. E. (2012). Executive and theory-of-mind contributions to event-based prospective memory in children: Exploring the self-projection hypothesis. Journal of Experimental Child Psychology, 111, 468-489.

Fortunato, V. J., \& Funey, J. T. (2011). The theory of Mind Time: The relationships between future, past, and present thinking and psychological wellbeing and distress. Personality and Individual Differences, 50(1), 20-24.

Gunther Moor, B., Macks, Z. A., Gueroglu, B., Rombouts, S. A. R. B., Molen, M. W., \& Crone, E. A. (2012).Neurodevelopmental changes of reading the mind in the eyes. Social Cognitive and Affective Neuroscience, 7, 44-52.

Hamidi, F, Shahmir, S, Mohammadi, N \& Dehnavi, E. (1391). Comparison of Creativity Approach among School Students and Conservatories Based on the Torrance Creativity Test. Innovation and creativity in humanities, Volume 2, Number 3. [Persian].

Kliegel, M., \& Martin, M. (2003). Prospective memory research: Why is it relevant? International Journal of Psychology, 38, 193194.

Leit, J. R., Morgan, C. J. A., Bisby, J. A., Rendell, P. G., \& Curran, H. V. (2009). Global impairment of prospective memory following acute alcohol. Psychopharmacology, 205, 379-387.

Mareike, A., Nora, V., Louise, C., Phillips, H., Akguin, C., Kliegel, M.(2014). Theory of mind and switching predict prospective memory performance in adolescents. Journal of Experimental Child Psychology.

Martin, T., McDaniel, M. A., Guynn, M. J., Houck, J. M., Woodruff, C. C., Bish, J. P., et al. (2007). Brain regions and their dynamics in prospective memory retrieval: A MEG study. Intermational Journal of Psychophysiology, 64, 247-258.

Nigro, G., Brandimonte, M. A., Cicogna, P.C., \& Cosenza, M.( 2013). Episodic future thinking as a predictor of children's prospective memory. Journal of Experimental Child Psychology. http://dx.doi.org/10.1016/j.jecp.2013.10.013.

Palette, J. 2010). Behavioral Sciences Data Analysis with SPSS Program with CD. Translation by Akbar Rezaei. Forouzou Publications. [Persian].

Paraskevaides, T., Morgan, C. J. A., Leitz, J. R., Bisby, J. A., Rendell, P. G., \& Curran, H. V. (2010). Drinking and future thinking: Acute effects of alcohol on prospective memory and 
future simulation. Psychopharmacology, 208, 301-308.

Rezaei, S., Manouchehri, M. (2008). Validity and Normalization of the Torrance Creativity Test among Teachers' High School Teachers. Joumal of Psychology and Education, 30(8), 47-63. [Persian].

Schacter, D. L., Addis, D. R., \& Buckner, R. L. (2008). Episodic simulation of future events: Concepts, data, and applications. Annals of the New YorkAcademy of Sciences, 1124, 39-60.

Sebastian, C. L., Fontaine, N. M. G., Bird, G., Blakemore, S. J., De Brito, S. A., McCrory, E. J. P., et al (2012). Neural processing associated with cognitive and affective theory of mind in adolescents and adults. Social Cognitive and Affective Neuroscience, 7, 53-63.

Simons, J. S., Scholvinck, M. L., Gilbert, S. J., Frith, C., \& Burgess, P. (2006). Differential components of prospective memory? Evidence from fMRI. Neuropsychologia, 44, 1388-1397.

Spreng, R. N., Mar, R. A., \& Kim, A. S. N. (2009). The common neural basis of autobiographical memory, prospection, navigation, theory of mind, and the default mode: A quantitative metaanalysis. Journal of Cognitive Neuroscience, 21, 489-510.

Stefan, W \& beat, M.(2014). How important is importancefor prospective memory?Areview Frontiers in Psychology. Cognitive Science June2014.Volume5.Article657.
Suddendorf, T., \& Corballis, M. C. (2007). The evolution of foresight: What is mental time travel and is it unique to humans? Behavioral and Brain Sciences,30(03), 299-313.

Szpunar, K. K. (2010). Episodic future thought: An emerging concept. Perspectives on Psychological Science, 5, 142-162.

Szpunar, K., Watson, J., \& McDermott, K. (2007). Neural substrates of envisioning the future. Proceedings of the National Academy of Sciences of the United States of America, 104, 642-647.

Torrance, E. P. (1966). Torrance Tests of Creative Thinking. Bensenville, IL: Scholastic Testing Service.

Torrance, P. (1979). Talents and creativity skills and ways to test them. Hassan Qasemzadeh's translation. Tehran: The New World Edition. [Persian].

Tse, C., \& Altamiba, J. (2007). Testing the associativelink hypothesis in immediate serial recall: Evidence from word frequency and word imageability effects. Memory, 15, 675-690.

Wang, L., Kliegel, M., Yang, Z. L., \& Liu, W. (2006). Prospective memory performance across adolescence. Journal of Genetic Psychology, 167, 179-188.

West, R., \& CraikF. I. M. (1999). Age-related decline in prospective memory: The roles of cue accessibility and cue sensitivity. Psychology \& Aging, 14, 264-272. 